\title{
A LICENCIATURA EM EDUCAÇÃO DO CAMPO E A ORGANIZAÇÃO CURRICULAR POR ÁREA DE CONHECIMENTO EM CIÊNCIAS DA NATUREZA
}

\author{
UNDERGRADUATE COURSE IN RURAL EDUCATION AND CURRICULAR \\ ORGANIZATION BY KNOWLEDGE AREA IN NATURE SCIENCES
}

\author{
Leila L. Paiter ${ }^{1}$ \\ Néli Suzana Britto
}

\begin{abstract}
Resumo: Este artigo é parte do resultado da dissertação de mestrado na área da Educação/Ensino em Ciências e tem como centralidade discutir sobre a formação docente por Área de Conhecimento em Ciências da Natureza no curso Licenciatura em Educação do Campo, da Universidade Federal de Santa Catarina - EduCampo/UFSC, com o objetivo de identificar e refletir sobre as características formativas orientadoras dessa proposta. Por meio dessa pesquisa foram elencadas três características formativas cenrais: a compreensão da realidade, a interdisciplinaridade e a seleção de conteúdos.
\end{abstract}

Palavras-chave: Educação do Campo; currículo por área de conhecimento; Ciências da Natureza; formação de professores.

\begin{abstract}
This paper is part of the result of the master's dissertation in the area of Education / Teaching in Sciences and its main focus is to discuss teacher education by Area of Knowledge in Natural Sciences in the Undergraduate Course in Rural Education, at the Federal University of Santa Catarina - EduCampo / UFSC, in order to identify and reflect on the guiding formative characteristics of this proposal. Through this research, three central formative characteristics were listed: understanding the reality, interdisciplinarity and content selection.
\end{abstract}

Keywords: Rural Education. Curriculum by Knowledge Area. Natural Sciences.

\section{Introdução}

As Licenciaturas em Educação do Campo (LEdoCs) trazem em seu cerne muitas questões que desafiam a repensar a educação brasileira, desde a educação básica até o ensino superior. Ao contrário da tradição de formação pela disciplinaridade de outras licenciaturas, a Educação do Campo propõe uma formação para a docência multidisciplinar a partir da organização curricular por Áreas de Conhecimento (AC).

Por se tratar de uma proposta ainda em consolidação, muitos desafios surgem na prática. Docentes formadores que nela atuam, são licenciados em campos disciplinares específicos, e se percebem em um curso com uma proposta diferenciada da licenciatura que cursaram. Nesse sentido, o estudo e discussão esteve pautado num aporte teórico que resgata alguns motivos que fazem as LEdoC terem uma organização curricular por AC e sobre as possibilidades de avançar ainda mais na formação de qualidade de educadores do campo.

Buscamos neste artigo refletir sobre a formação por AC em Ciências da Natureza $(\mathrm{CN})$, mais especificamente no curso de Licenciatura em Educação do Campo da Universidade Federal de Santa Catarina (EduCampo/UFSC). Para isso, iniciamos a abordagem sobre a origem da formação por AC na criação das LEdoCs. Em seguida, são apresentadas algumas características formativas que acompanham essa proposta e também

\footnotetext{
${ }^{1}$ Secretaria Municipal de Educação, Alfredo Wagner, SC, Brasil.

${ }^{2}$ Universidade Federal de Santa Catarina, Florianópolis, SC, Brasil.
} 
alguns desafios prático-pedagógicos em sua concretização na formação docente por Área de conhecimento em Ciências da Natureza.

\section{A proposta de uma licenciatura em Educação do Campo com formação por área de conhecimento}

Inicialmente, Caldart (2011) chama atenção de que a centralidade do Projeto Político Pedagógico das LEdoCs não está e não deve estar na AC, pois essa foi uma das ferramentas escolhidas dentro das circunstâncias históricas determinadas para desenvolver um projeto de formação de educadores comprometida com caminhos para a transformação da escola do campo. O debate da docência por AC, ao ser absolutizado, descentraliza a discussão de aspectos centrais e as finalidades formativas que devem orientar o curso, ou seja, que possuem uma dimensão maior.

A decisão de desconsiderar um curso de licenciatura com estruturas disciplinares teve como base dois principais motivos. O primeiro diz respeito a uma questão prática e de logística nas áreas rurais, pois,

[...] um dos problemas alegados para garantir escolas de Educação Básica completa nas comunidades camponesas é a inviabilidade de manter um professor por disciplina em escolas que nem sempre conseguem ter um número grande de estudantes e cuja localização torna mais difícil a lógica de cada professor trabalhar em diversas escolas para completar sua carga horária. (CALDART, 2011, p. 106).

O segundo motivo, estava relacionado com a própria descaracterização dos princípios que estavam sendo discutidos, uma vez que, se fosse

[...] uma licenciatura disciplinar (especialmente do ponto de vista de legislação e diretrizes curriculares já consolidadas ainda que com muitas críticas) seria muito difícil conseguir aprovar as subversões necessárias na lógica do curso, em vista dos objetivos formativos mais amplos. (CALDART, 2011, p. 106).

E ainda,

[...] o tratamento da especificidade do campo ou não seria aceito ou o seria da forma mais equivocada possível, considerando a diferenciação nos próprios conteúdos disciplinares (teríamos uma Geografia do campo ou uma Física do campo), algo que as concepções originárias da Educação do Campo sempre combateram com veemência. (CALDART, 2011, p. 106)

Tal afirmação vem ao encontro das considerações de Goodson (2001) sobre uma tradição acadêmica já consolidada na formação de professores, na qual se prevê de forma hegemônica a formação em campos disciplinares. Deste modo, estava em jogo a aprovação de uma licenciatura que buscava romper com fronteiras demarcadas por tradições disciplinares, ou seja, que desafiava a ordem hegemônica já estabelecida nas universidades e escolas.

Do ponto de vista legal, as LEdoCs tiveram subsídio nas Diretrizes Curriculares Nacionais para a formação de professores da Educação Básica (BRASIL, 2015). Contudo, Caldart (2011, p. 107) destaca que "não se optou por uma Licenciatura por área $[\mathrm{AC}]$ e, sim, pela formatação de uma Licenciatura em Educação do Campo, efetivamente uma nova 
concepção de Licenciatura". Afinal, já se tinha a análise de que a AC em si mesma não alteraria os limites identificados nas licenciaturas disciplinares.

Segundo Molina e Sá (2013, p. 469), a intencionalidade maior da formação docente por AC é "contribuir com a construção de processos capazes de desencadear mudanças na lógica de utilização e de produção de conhecimento no campo". Desse modo, um dos desafios postos é a ruptura das "tradicionais visões fragmentadas do processo de produção de conhecimento, com a disciplinarização da complexa realidade socioeconômica do meio rural na atualidade" (MOLINA; SÁ, 2013, p. 469). Nesse sentido, a organização dos componentes curriculares em $\mathrm{AC}$, se refere a organização de

[...] novos espaços curriculares que articulam componentes tradicionalmente disciplinares por meio de uma abordagem ampliada de conhecimentos científicos que dialogam entre si a partir de recortes complementares da realidade. Busca-se [...], superar a fragmentação [...] e mudar o modo de produção do conhecimento na universidade e na escola do campo, tendo em vista a compreensão da totalidade e da complexidade dos processos encontrados na realidade (MOLINA; SÁ, 2013, p. 469).

Nesse sentido, a formação docente precisará garantir o domínio das bases das ciências a que correspondem às disciplinas que compõem a sua área de habilitação. No entanto, não pode ficar restrita às disciplinas convencionais, as quais seguem a lógica segmentada predominante nos currículos da Educação Básica e também na Educação Superior. Diante disso, as disciplinas não são o objetivo central do trabalho pedagógico com o conhecimento, mas sim, as questões da realidade como objeto de estudo, que tem como base a apropriação do conhecimento científico já acumulado (MOLINA; SÁ, 2013).

A partir dessa afirmação, destacamos uma argumentação recorrente não só entre os estudiosos da Educação do Campo, e, de modo geral, estudos sobre educação: o modo como a escola e seu currículo estão organizados se mostram insuficientes para que estudantes compreendam a materialidade, as contradições sociais, a realidade existente. Nesse sentido, a formação docente das LEdoCs questiona os modos de produção e apropriação do conhecimento historicamente produzido e transposto nos processos escolares. Assim, a formação por AC também traz em sua essência a crítica em relação a essa fragmentação do ensino.

Severino (2011, p. 148) afirma que essa fragmentação se expressa de várias formas, sendo que a primeira está relacionada aos conteúdos dos diversos componentes curriculares e às atividades didáticas, as quais não se integram, "como se os elementos culturais que dão conteúdo ao seu saber fossem estanques e oriundos de fontes isoladas entre si”. Assim, as ações docentes, atividades técnicas e intervenções administrativas também não conseguem se articular em uma unicidade, é como se cada uma tivesse seu próprio fim. Cabe pontuar mais uma expressão marcante dessa fragmentação, a verdadeira ruptura entre discurso teórico e a prática real, destacando que

[...] É possível identificar como vinculada a essa fragmentação generalizada a desarticulação da vida da escola com a vida da comunidade a que serve, do pedagógico com o político, do microssocial com o macrossocial. Tudo se passa como se se tratasse de dois universos autônomos, desenvolvendo-se paralelamente, intercomunicando-se apenas de maneira formal, mecânica, burocrática, como se entre escola e comunidade não houvesse um cordão umbilical. (SEVERINO, 2011, p. 149). 
Tais considerações apontam para distanciamentos que a fragmentação tem provocado nas relações estabelecidas entre escola e comunidade, separando olhar pedagógico e as relações sociais, políticas, econômicas e ambientais, que são externas à escola, porém intimamente relacionadas. Severino (2011) nos chama atenção para o desafio a ser enfrentado: pensar e agir de modo mais articulado com as diferentes esferas de relacionamento que uma escola (e também universidade) exige.

A formação por AC é compreendida como uma possibilidade para promover mudanças mais concretas nas escolas do campo, com o objetivo de contribuir para o rompimento da lógica hegemônica em que a maioria dos sistemas escolares estão organizados. Por sua vez, tais mudanças estavam relacionadas à constituição de equipes docentes (por AC) para fortalecer o trabalho integrado, se contrapondo à lógica da fragmentação e ao afastamento da realidade. Desta forma, a AC poderia ser uma ferramenta relevante para promover outra organização curricular nas escolas do campo (CALDART, 2011). E, nas LEdoCs, as AC enquanto uma forma de organização curricular e/ou como método de trabalho pedagógico, sem serem excludentes (MOLINA; SÁ, 2013).

Assim, tais pressupostos dão origem à proposição da formação docente por $\mathrm{AC}$ nas LEdoCs. São orientadores de seu processo formativo enquanto uma proposta teórica e prática aos diversos desafios que vêm sendo postos, principalmente no que tange à uma educação que aproxime o Ensino em CN e a realidade dos sujeitos do campo. Apresentamos, a seguir, o conjunto de três características - a compreensão da realidade; a interdisciplinaridade; e a seleção dos conteúdos - que estão inter e intra-relacionadas na proposta de formação docente por AC nas LEdoCs, enquanto pressupostos dessa perspectiva ${ }^{3}$.

\section{A compreensão da realidade}

A formação docente por AC como um fim em si mesma não alteraria as dificuldades já encontradas nas demais licenciaturas, por isto que, tanto Caldart $(2011,2015)$ quanto Molina e Sá (2013) e Molina (2014a, 2014b), ressaltam um aspecto chave que caracteriza as LEdoCs: a compreensão da realidade (CR).

Cabe destacarmos que a CR nos cursos de LEdoCs, implica em considerar, nos processos de ensino e aprendizagem, as questões relacionadas à vida dos sujeitos. O que não se trata de abordar apenas o cotidiano ou usar a realidade como contextualização para justificar o ensino de determinados conteúdos pré-estabelecidos, mas sim de abordar questões presentes na realidade da comunidade.

Nesse sentido, também está se aludindo à necessidade de problematizar essa realidade, para assim compreender os conflitos, as injustiças, as contradições sociais, ambientais e econômicas que estão inter-relacionadas com os sujeitos do campo, em esfera micro e macro sociais (SILVA, 2007). Pois, "a realidade concreta é algo mais que fatos ou dados tomados mais ou menos em si mesmos. Ela é todos esses fatos e todos esses dados e mais a percepção que deles esteja tendo a população neles envolvida" (FREIRE, 1987, p. 35).

Conhecer a realidade concreta, segundo Freire (1987) é ir além e tentar compreender a percepção da própria população sobre a realidade em que vive. Desse modo, ao considerar a visão dos sujeitos sobre a própria realidade, também se constrói uma educação pensada a partir e com os povos do campo e não para esses povos.

Na CR está imbricada a superação de processos desumanizadores, pois não se trata do sujeito agir como mero expectador, mas como alguém ciente das contradições socioculturais

\footnotetext{
${ }^{3}$ As três características também são críticas ao ECN convencional, ao modo como vem sendotratado o ECN nas escolas e na formação de professores.
} 
que o envolve - e das quais é também co-produtor (BRICK, 2017) —, seja sujeito de interferência e/ou de transformação. Em síntese, a CR concreta pode ter como ponto de partida a investigação da realidade local ${ }^{4}$, sem desconsiderar sua relação com a esfera micro e macro, local e global, desde que se tenha criteriosa investigação das contradições sociais que impedem os sujeitos de serem construtores de sua própria história.

Sob tais estudos afirmamos que a CR é propulsora de toda luta pela Educação do Campo. A centralidade destas licenciaturas está na realidade concreta, a qual tem em suas entrelinhas inúmeras situações históricas e atuais de desigualdade, injustiça e sofrimento dos povos do campo. Em síntese, essa compreensão pressupõe entendermos que a realidade concreta está em movimento dinâmico, deve ser considerada mediatizadora para problematização de situações desumanizadoras e, por isso, um critério para a seleção de conteúdos a serem trabalhados. Enquanto sujeito histórico real, é necessário entendermos que a leitura da realidade também é feita pelas comunidades, pelos sujeitos daquele local. E ainda reiterar o cuidado que se deve ter ao partir do local, desconsiderando relações imprescindíveis entre esses conhecimentos e o conhecimento historicamente sistematizado.

\section{A interdisciplinaridade}

Com base nas considerações feitas sobre a CR, principalmente a crítica sobre sua excessiva fragmentação do ensino, outra característica que acompanha a perspectiva de formação docente por AC nas LEdoCs é a interdisciplinaridade.

Sob esse foco proposto pela Educação do Campo, enfatizamos que sejam desenvolvidos processos educativos por meio de práticas interdisciplinares que envolvam os conhecimentos específicos das ciências de referência: Física, Química, Biologia e também da Matemática, conforme veremos no exemplar apresentado adiante nesse texto, onde os conhecimentos selecionados são indispensáveis para compreender a materialidade dos próprios problemas reais e concretos a serem enfrentados no campo e com todas as contradições que envolvem esses sujeitos, contribuindo na melhor compreensão de determinados fenômenos que se deparam (MOLINA, 2014b).

De acordo com Frigotto (2008, p. 12), a interdisciplinaridade não deve ser tratada apenas "dentro de uma ótica fenomênica, abstrata e arbitrária, em que aparece como sendo um recurso didático capaz de integrar, reunir as dimensões particulares dos diferentes campos científicos ou dos diferentes saberes numa totalidade harmônica", pois a necessidade dela (interdisciplinaridade) é de caráter dialético da realidade social, ou seja, em constante e permanente diálogo com a realidade concreta.

Ao afirmar que a interdisciplinaridade é condição da prática social, se entende que a CR também é um processo interdisciplinar, sendo historicamente as especialidades uma forma de explicar a realidade, de separar e aprofundar estudos para melhor conhecer objetos e fenômenos. Mas, ao transpor essa ideia para o ensino, corremos alguns riscos, pois o ensino de determinados conteúdos com finalidade em si mesmos, sem conexão com "a vida dos estudantes" e sem relação com a totalidade na qual estão inseridos, podem tornar-se tão descontextualizados e fragmentados a ponto de perder o sentido e a importância para os estudantes e também para os professores.

Deste modo, compreendemos que a interdisciplinaridade não se trata apenas de explicar os fenômenos sob diferentes visões ${ }^{5}$, mas sim de desvelar as desigualdades, as contradições

\footnotetext{
${ }^{4}$ O Regime de Alternância na proposição das LEdoCs pode ser considerado uma importante característica, pois pode proporcionar a dinâmica entre teórica e prática que orienta o estudo dessa realidade

${ }^{5}$ Reconhecemos que "apenas" essa explicação já é uma grande contribuição, mas não suficiente na perspectiva que nos orienta.
} 
sociais, aquilo que impede o ser humano de "ser mais" (FREIRE, 1987). Por isso, o trabalho interdisciplinar tem como ponto de partida a investigação/problematização da realidade.

Como exemplo, apresentamos abaixo o exercício realizado durante o processo de formação continuada com um coletivo de professoras da Educação Básica ${ }^{6}$. A partir do processo de CR chegamos a uma problemática que impedia muitos sujeitos de se perceberem enquanto capazes de transformar aquela realidade.

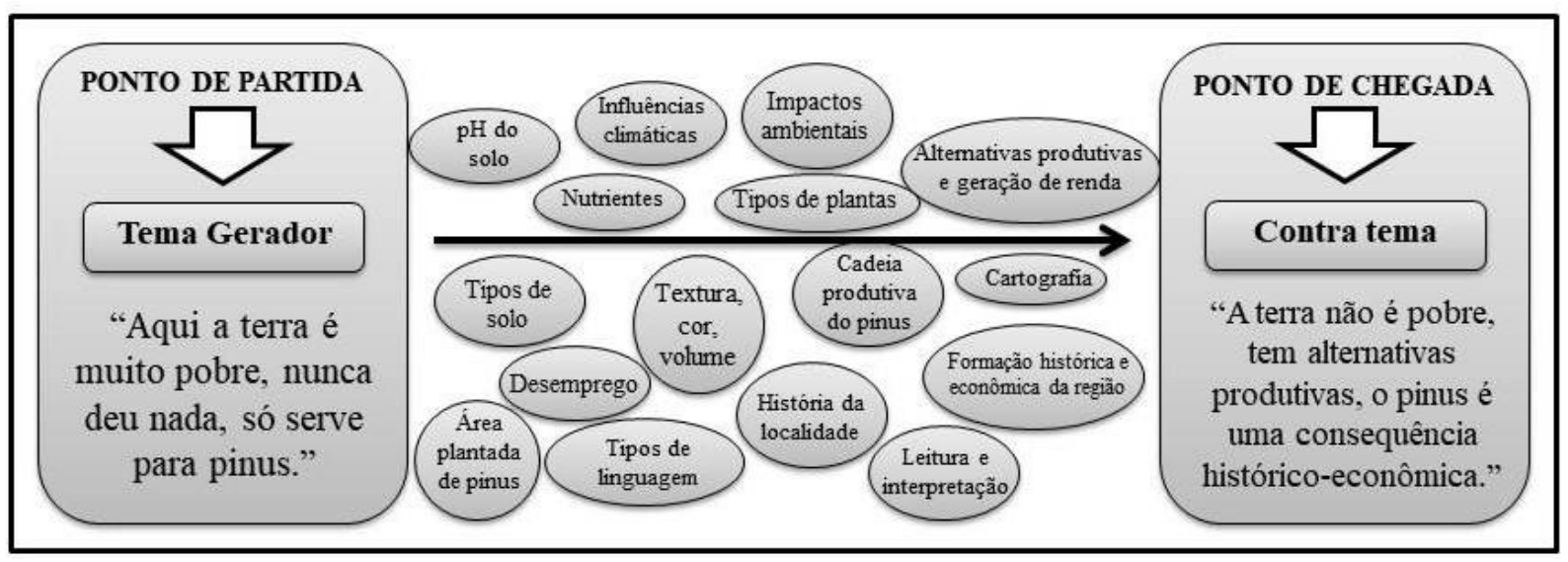

Figura 1: Exercício de planejamento interdisciplinar e seleção inicial de conhecimentos - Fonte: Adaptado de PAITER (2016).

O ponto de partida foi uma problemática presente na realidade concreta daqueles sujeitos, que nesse caso traz a contradição de ter o acesso a terra, mas por conta das condições precárias não se produzia nela. A opção geralmente percebida pelos sujeitos era alugar para o plantio de pinus ${ }^{7}$, uma monocultura que traz em seu modo de produção a exploração dos trabalhadores e também o esvaziamento populacional do campo, devido à falta de alternativas produtivas que sejam capazes de competir com o modelo vigente, além de grave degradação do solo e de toda biodiversidade.

O ponto de chegada é a visão crítica dos educadores, educandos e de outros atores sociais que participassem desse processo. O trabalho coletivo interdisciplinar é o meio, é onde os educadores a partir de seus campos disciplinares ou AC selecionarão conhecimentos que contribuirão para desvelar as contradições e construir uma nova visão para a problemática e possíveis soluções para sua superação.

Desse modo, a interdisciplinaridade enquanto parte do processo de CR, o qual por se tratar de uma investigação ampla, necessita de outra peça chave, o trabalho coletivo interdisciplinar, desde o ponto de partida, durante o processo e até o ponto de chegada delimitado. Logo, a interdisciplinaridade requer o olhar de várias áreas do conhecimento e especialidades para a problematização e apreensão ${ }^{8}$ da realidade, é um trabalho que caminha concomitante entre e com o olhar crítico do coletivo de docentes em diálogo permanente com os educandos. Por isso, é tão necessário quando se fala em interdisciplinaridade o planejamento coletivo, para que cada respectivo campo disciplinar faça a seleção e a abordagem de conhecimentos significativos para a transformação da realidade concreta.

\footnotetext{
${ }^{6}$ Esse exercício foi realizado com as professoras da E. E. B. Luiz Bernardo Olsen e E. M. E. B. Padre Cláudio Longen (Rio Negrinho/SC) durante a Especialização Latu Sensu para o Trabalho Interdisciplinar em Ciências da Natureza e Matemática (PAITER, 2016).

${ }^{7}$ Espécie de árvore plantada em grande escala com o objetivo de produzir madeira e celulose.

${ }^{8}$ Freire (2015, p. 67), ao tratar sobre "apreensão da realidade", aponta que a capacidade de aprender não é "apenas para nos adaptar, mas sobretudo para transformar a realidade, para nela intervir, recriando-a”.
} 
Ressaltamos que as discussões sobre a interdisciplinaridade nas LEdoCs não têm a finalidade de reivindicar a supressão do estudo das disciplinas já consolidadas e não nega o conhecimento historicamente produzido por elas — ciências de referência —, mas têm a intencionalidade inicial de contribuir com a ressignificação das estratégias de seleção e o modo de abordagem dos conhecimentos por elas gerados. Deste modo, trabalho interdisciplinar pressupõe:

[...] que as várias ciências deveriam contribuir para o estudo de determinados temas que orientariam todo o trabalho escolar. Respeita a especificidade de cada área do conhecimento, isto é, a fragmentação necessária no diálogo inteligente com o mundo e cuja gênese encontra-se na evolução histórica do desenvolvimento do conhecimento. Nesta visão de interdisciplinaridade, ao se respeitar os fragmentos de saberes, procura-se estabelecer e compreender a relação entre a totalização em construção a ser perseguida e continuamente a ser ampliada pela dinâmica de busca de novas partes e novas relações. (DELIZOICOV; ZANETIC, 1993, p. 13).

Tal movimento pode levar à compreensão da realidade a ponto de que os sujeitos do processo consigam enxergarem-se como sujeitos capazes de intervir e transformar, atuando para além de meros expectadores no tempo histórico.

A complexidade dessas relações que a realidade concreta nos apresenta demanda uma visão de totalidade. Por conta disso, essa demanda exige uma formação que dê conta, dessa complexidade, e a formação docente por AC aponta para um possível caminho.

Na perspectiva da Educação do Campo, a interdisciplinaridade faz parte de um processo mais amplo, que constitui a CR, ou seja, não se dá somente pela articulação a partir da abstração dos campos disciplinares, mas sim pelo seu caráter dialético da realidade social, contribuindo para a construção de uma visão de totalidade desses processos nos quais os educandos estão inseridos. Por isso, o seu ponto de partida é a investigação e problematização da realidade concreta, sob o ponto de vista crítico de um coletivo interdisciplinar, no qual se buscam novas relações e articulações, vislumbrando como ponto de chegada o desvelamento de contradições sociais presentes. Esse processo está associado a uma mudança no modo de como o sujeito percebe, entende e age diante da realidade.

\section{A seleção de conteúdos}

Molina (2014b) afirma que a formação por AC objetiva contribuir com a transformação dos planos de estudos, possibilitando, desta forma, a criação de novas estratégias de seleção de conteúdos, aproximando-os da realidade e promovendo também o trabalho docente coletivo. Contudo, a discussão da $\mathrm{AC}$ em $\mathrm{CN}$, não faria sentido se não tivesse uma questão orientadora mais ampla, a qual se refere diretamente:

[...] a colocação do conhecimento científico a serviço da vida, das condições de profunda desigualdade e injustiça vigente no campo brasileiro, decorrente da intensificação e agravamento do modelo agrícola hegemonizado pelo agronegócio, que cada vez mais desterritorializa os sujeitos camponeses, em busca de terras para o seu domínio, para neles implantar mais monoculturas, [...] e obter mais lucro! Qual a relação das Ciências da Natureza com esses processos? Em que medida os conteúdos do ensino de Biologia, de Química, de Física relacionam-se com essas questões? (MOLINA, 2014b, p. 17). 
Essas indagações contribuem para ressignificar as estratégias de seleção de conteúdos a serem trabalhados, tanto nos cursos de formação docente quanto nas escolas do campo. Tal perspectiva busca um processo de ensino e aprendizagem que supere a fragmentação do conhecimento, possibilitando a ampliação da compreensão da realidade pelos educandos e educadores sob uma visão totalizadora dos processos sociais (MOLINA, 2014b), para propiciar intervenções transformadoras na realidade injusta e desigual.

Recorremos a Delizoicov (1991) e sua contribuição com a discussão sobre o significado de "conteúdo" no âmbito da educação escolar:

[...] o termo conteúdo pode levar à interpretação de que o conhecimento universal sistematizado se reduz ao conteúdo veiculado por livros didáticos e programas escolares já estabelecidos e usados na prática docente; e, como uma possível consequência, uma primeira redução: a do objeto e do conhecimento como sendo idênticos por justaposição e, além disso, reduzido a esses conteúdos. (DELIZOICOV, 1991, p. 129).

O autor enfatiza que deve "haver critérios para que se estabeleçam quais objetos e para que se selecionem os consequentes conhecimentos sobre eles construídos" (DELIZOICOV, 1991, p. 129). É necessário questionar "o que" do conhecimento universal cabe vincular aos conteúdos escolares, rompendo com a tradição de conteúdos já pré-estabelecidos, proporcionando assim um novo olhar sobre "o que ensinar" e "para quem" ensinar. Pois além de ser um patrimônio universal, esse deve ser desenvolvido na educação escolar, porque o seu processo de construção, sua historicidade e sua instrumentabilidade possibilitam a compreensão dos problemas sócio-historicamente determinados na comunidade (DELIZOICOV, 1991).

Logo, se fazemos a crítica ao modelo predominante da escola atual e ao seu currículo, não faz sentido, na formação docente reforçar o ensino de conteúdos (justapostos) exigidos a serem ensinados por ela (a escola $)^{9}$, pois para que seja transformada, é necessário também repensarmos as estratégias de seleção de conteúdos relevantes socio-historicamente. Delizoicov (1991) destaca que nem todo conhecimento universal tem caráter transformador.

O conhecimento construído deve ser uma consequência da análise da realidade e não a recepção passiva de teorias genéricas "aprioristicamente" selecionadas por especialistas. Assim, resgatar a importância de estabelecer critérios críticos para a seleção dos objetos de estudo e dos respectivos conhecimentos demandados para apreensão concreta do real são exigências para qualquer prática de educação popular efetivamente comprometida com a humanização. Tais conhecimentos devem propiciar uma superação nas visões de mundo, ou seja, na passagem da cultura ingênua à crítica. É no processo coletivo de teorização que a realidade se desvela em sua concretude (SILVA, 2007, p. 18).

Corroboramos que a seleção de conteúdos não deve ser encarada enquanto algo pronto e acabado, mas sim como um processo, da mesma forma como a CR e a interdisciplinaridade. É com base no estudo da realidade concreta, sob um olhar criterioso do coletivo de docentes, de estudantes e também da comunidade, que é possível realizar a seleção dos conteúdos socialmente relevantes que irão compor o currículo, sendo o estudo de conceitos científicos um modo de buscar a superação das contradições vivenciadas pelos sujeitos nas suas comunidades na efetiva transformação da realidade concreta.

\footnotetext{
${ }^{9}$ Isso não significa que não se devem ensinar conteúdos já pré-determinados pela escola, mas que é necessário um olhar crítico sobre eles e as suas intencionalidades.
} 
Apresentamos características que podem ser pressupostos da formação docente por AC na LEdoC. Mas, por onde começar? Destacamos a aproximação dessas características formativas com o processo de Investigação Temática (IT) de Freire (1987), evidenciando assim, um possível caminho para a organização do trabalho pedagógico por $\mathrm{AC}$ em $\mathrm{CN}$.

A IT é um processo de educação popular crítica, que integra uma metodologia teóricopedagógica que precisa ser construída dialogicamente com o povo para selecionar Temas Geradores ${ }^{10}$. O que implica no respeito às visões de mundo e aos saberes dos educandos, e o "diálogo entre saberes popular e científico, em que a apreensão do conhecimento é construída coletivamente, a partir da análise das contradições vivenciadas na realidade local” (SILVA, 2013, p. 76).

Essas contradições vivenciadas na realidade local se referem a "situações limites" que se apresentam como obstáculos para a emancipação do ser humano. Sendo assim, um desafio na perspectiva de uma educação humanizadora reconhecer a realidade sociocultural-econômica injusta e desigual e também superar visões fatalistas e imobilistas.

\section{Ponderações finais}

Buscamos apontar algumas reflexões por meio de caminhos teóricos e práticos que contribuem para compreendermos o que significa a formação docente por $\mathrm{AC}$ em $\mathrm{CN}$. O olhar para a EduCampo/UFSC reuniu um conjunto de dados que possibilitaram um melhor entendimento sobre o processo formativo por AC nas LEdoCs.

Ao ponderarmos que o modo como vem se constituindo essa formação na EduCampo/UFSC traduz aspectos que se aproximam mas também se afastam de pressupostos da formação por AC na perspectiva da Educação do Campo. Dentre os aspectos que se afastam evidenciamos por vezes o distanciamento da realidade concreta e também a ausência do trabalho interdisciplinar no planejamento de algumas práticas educativas, implicando assim na seleção de conteúdos em alguns momentos desvinculados da realidade concreta dos estudantes.

Mas é importante também evidenciarmos os aspectos que se aproximam dos pressupostos da formação docente por $\mathrm{AC}$, tais como a preocupação dos docentes formadores de alguma forma articular a realidade, mesmo tendo diferentes pontos de partida, o que aponta esforço de abordar conteúdos e relacioná-los com um entendimento de "realidade", buscando critérios para não tratar os conteúdos com um fim em si mesmos, uma decisão que tensiona uma tradição disciplinar advinda de suas formações iniciais e das demandas escolares.

Com o objetivo de refletir sobre a formação por AC apresentamos o exemplar de uma experiência de planejamento coletivo, que mostra parte do movimento de Investigação Temática e que em sua construção evidencia a presença e a inter-relação das características formativas: compreensão da realidade, interdisciplinaridade e seleção de conteúdos.

Vale reforçarmos a necessidade de aprofundar os estudos de práticas educativas que indicam caminhos metodológicos que contribuem com a qualidade da formação docente por AC em CN nas universidades e nesse mesmo sentido, que embasem o trabalho pedagógico nas escolas do campo, visando a transformação curricular e organizacional com o objetivo maior, de outro projeto de sociedade.

\footnotetext{
${ }^{10}$ Essa metodologia teórico-pedagógica foi orientadora da Especialização Latu sensu em Educação do Campo para o Trabalho Interdisciplinar em C N e MTM" e consistiu em estudos mais aprofundados sobre as etapas da Investigação Temática Freireana.
} 


\section{Referências}

BRASIL, Ministério da Educação. Resolução CNE/CP No 02, de 01 de julho de 2015. Define as Diretrizes Curriculares Nacionais para formação inicial em nível superior (Cargos de licenciatura, curso de formação pedagógica para graduados e cursos de segunda licenciatura) e para formação continuada. Diário Oficial da União, Brasília, 2015.

BRICK, Elizandro Maurício. Realidade e Ensino de Ciências. 2017. Tese (Doutorado em Educação) - Programa de Pós-Graduação em Educação Científica e Tecnológica, UFSC, Florianópolis, 2017.

CALDART, R. S. Licenciatura em Educação do Campo e projeto formativo: qual o lugar da docência por área? In: MOLINA, M. C.; SÁ, L. M. (Org.). Licenciaturas em educação do campo: registros e reflexões a partir das experiências-piloto (UFMG; UnB; UFBA e UFS). Belo Horizonte: Autêntica Editora, 2011. Coleção Caminhos da Educação do Campo 5. p. 95-121.

CALDART. Pilares Fundantes de uma nova forma escolar. In: Caderno de estudos do 5 Seminário Nacional das Licenciaturas em Educação do Campo. Laranjeiras do Sul - PR: 2015.

DELIZOICOV, D. Conhecimento, tensões e transições. 1991. Tese (Doutorado em Educação) - Faculdade de Educação, Universidade de São Paulo, São Paulo, 1991.

DELIZOICOV, D.; ZANETIC, João. A proposta de interdisciplinaridade e o seu impacto no ensino municipal de $1^{\circ}$ grau. In: PONTUSCHKA, N. N. Ousadia no Diálogo: Interdisciplinaridade na Escola Pública. São Paulo: Loyola, 1993. p. 9-15.

FREIRE, P. Pedagogia da Autonomia - Saberes Necessários à Prática Educativa. 3. ed. Rio de Janeiro: Paz e terra, 2015.

FREIRE, P. Pedagogia do Oprimido. 17. ed. Rio de Janeiro: Paz e terra, 1987.

FRIGOTTO, G. A interdisciplinaridade como necessidade e como problema nas ciências sociais. Revista do Centro de Educação e Letras da UNIOESTE, Campus de Foz do Iguaçu, v. 10, n. 1, p. $41-62,1^{\circ}$ semestre de 2008.

GOODSON, I. F. Currículo, teoria e história. Tradução de Atília Brunetta; apresentação de Tomaz Tadeu da Silva. 8. ed. Petrópolis, RJ: Vozes, 2001.

MOLINA, M. C. Análises de Práticas contra-hegemônicas na formação de Educadores: reflexões a partir do Curso de Licenciatura em Educação do Campo. In: SOUZA, José Vieira (Org.). O método dialético na pesquisa em Educação. Campinas: Autores Associados. 2014a.

MOLINA, M. C. Apresentação. In: MOLINA, M. C.; SÁ, L. M. (Org.). Brasília - DF. MDA, NEAD. Licenciaturas em Educação do Campo e o ensino de Ciências Naturais: desafios à promoção do trabalho Interdisciplinar. 2014b. 
MOLINA, M. C.; SÁ, L. M. Licenciatura em Educação do Campo. In: CALDART, R. S. et al. (Org.). Dicionário da Educação do Campo. 3. ed., reimpr. Rio de Janeiro, São Paulo: Escola Politécnica de Saúde Joaquim Venâncio/Fiocruz, Expressão Popular, 2013. p. 466-472.

PAITER, L. L. Educação do campo e a perspectiva freireana: reflexões sobre o trabalho docente em aulas de Ciências da Natureza e na formação de professoras no município de Rio Negrinho/SC. 2016. TCC (Especialização Latu Sensu em Educação do Campo e para o Trab. Interdisciplinar em CN e MTM) - Faculdade UnB Planaltina/CTEC, Universidade de Brasília, 2016.

PAITER, L. L. Reflexões sobre a formação docente na área de conhecimento Ciências da Natureza: a Licenciatura em Educação do Campo. Dissertação de Mestrado - Programa de PósGraduação em Educação Científica e Tecnológica, Universidade Federal de Santa Catarina, Florianópolis, SC, 2017.

SEVERINO, A. J. O uno e o multiplo: o sentido antropológico do interdisciplinar. In: FRIGOTTO et al. (Org.). Interdisciplinaridade: para além da filosofia do sujeito. 9. ed. Petrópolis, Rio de Janeiro: Vozes, 2011.

SILVA, A. F. G. A busca do tema gerador na práxis da educação popular/Antônio Fernando Gouvêa da Silva; organizadora: Ana Inês Souza. Curitiba: Editora Gráfica Popular, 2007. 208 p.

SILVA, A. F. G. O currículo na práxis da Educação Popular: Projeto Pedagógico Interdisciplinar Tema Gerador via Rede Temática. In: PERNAMBUCO, M. M. C. A.; PAIVA I. A. Práticas Coletivas na Escola. Campinas, SP: Mercado de Letras; Natal, RN: UFRN, 2013.

\section{Sobre as autoras}

Leila Paiter: Licenciada em Educação do Campo pela Universidade Federal de Santa Catarina - UFSC - (2013), Mestre em Educação Científica e Tecnológica pela UFSC (2017) e segunda licenciatura em Pedagogia pelo Centro Universitário Leonardo da Vinci (2020). Atuação na rede municipal de Alfredo Wagner como educadora no Projeto Meio Ambiente. Experiência e pesquisas na área de EduCampo e Ensino de Ciências; Estudos Freireanos; Educação Ambiental e formação docente por AC no âmbito das LEdoCs.

E-mail: leila01paiter@gmail.com.

Néli Suzana Britto: Graduada em Ciências Biológicas: Licenciatura em Ciências pela Universidade Federal do Rio Grande do Sul (1987), mestrado em Educação pela Universidade Federal de Santa Catarina (2000) e doutorado em Educação pela Universidade Federal de Santa Catarina (2010). Atuação como docente na Licenciatura em Educação do Campo da Universidade Federal de Santa Catarina (aposentada em 2019). Professora e pesquisadora no Programa de Pós Graduação em Educação Cientifica e Tecnológica na Universidade Federal de Santa Catarina (voluntária em 2020).

E-mail: nelisb3@hotmail.com. 